\title{
The simulation analysis of the pressure in the silo influence on the structure of the grain dryer
}

\author{
Yang Wang ${ }^{a}$, Yan Zhou ${ }^{b}$ \\ College of Engineering and Technology, Jilin Agricultural University, Changchun 130118; \\ awangyang800507@126.com, b359953768@qq.com
}

Keywords: Grain drying machine; Saturated pressure; Finite element; Rectangular silo; Simulated analysis

Abstract. This paper we intend to test the pressure during the process of grain drying in the rectangular silo and explore the change regularity of dynamic and static pressure. According to the trend of the dynamic and static pressure with height, we analyzed the pressure and the structure stress in the silo that could have effects on the structure of grain drying machine by the finite element analysissoftware. We obtain the relationship of the dynamic and static pressure between the corn moisture content through contrasting the result of the experiment and the finite element simulated analysis.

\section{Introduction}

When we filled particles within the silo, the bottom pressure of the silo was not increased linearly with the filling height like filled liquid. But filled to a certain height, it could reach a saturation value ${ }^{[1-2]}$. The phenomenon was derived from the particle tangential friction force between the particle medium and the silo wall ${ }^{[3-4]}$.

In this paper, we analyzed the change rule of grain storage pressure and the correlation between the stress and the grain moisture. At the same time, we carried out the optimized analysis on the structure of the grain dryer using the change law of pressure in the silo. We put forward a new method of detecting the grain moisture by pressure.

\section{The influence of moisture content changes on the pressure in the silo}

The corns were used by artificial humidifying method due to the limitation of the season and soaked $12 \mathrm{~h}$ in the water. Then the corns were precipitated by drying. The samples of the different moisture content would be filled according to the above method. With the change of the filling height, the curve of the stress change was shown in Fig.1.

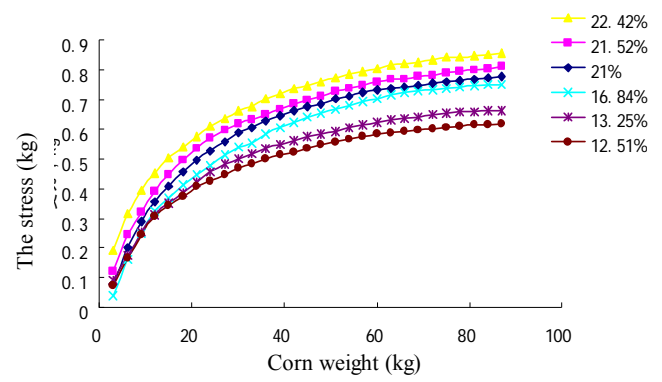

Fig.1 The influence of the different moisture content to force change

It showed that with the increase of moisture content, the stress was also constantly increased and the force change trend was consistent on the different moisture content. Between the pressure and the corn weight and had obvious index relationship with the change of moisture content. 


\section{The simulation analysis}

The rectangular silo was modeling using Pro/E. The model would be built and imported into the finite element structural static analysis in ANSYS workbench ${ }^{[5-6]}$. The material of the rectangular silo was used by the carbon steel. The material parameters of steel were shown in Table 1.

Table 1 The material parameters of steel

\begin{tabular}{ccccc}
\hline Density & Young modulus & Poisson'sratio & Bulkmodulus & Shearmodulus \\
\hline $7.85 \mathrm{e}-006 \mathrm{~kg} / \mathrm{m}^{3}$ & $2 . \mathrm{e}+11 \mathrm{~Pa}$ & 0.3 & $1.6667 \mathrm{e}+11 \mathrm{~Pa}$ & $7.6923 \mathrm{e}+10 \mathrm{~Pa}$ \\
\hline
\end{tabular}

Due to the moisture content of corn was different; its density was also different. Choose the corns of the different density as the research object such as $710 \mathrm{~kg} / \mathrm{m}^{3}, 610 \mathrm{~kg} / \mathrm{m}^{3}, 510 \mathrm{~kg} / \mathrm{m}^{3} 、 410 \mathrm{~kg} / \mathrm{m}^{3}$. The undersurface of silo and different height deformation were shown in Fig. 2. The deformation of the $710 \mathrm{~kg} / \mathrm{m}^{3}$ density was shown in Fig.2(a). The deformation of the $610 \mathrm{~kg} / \mathrm{m}^{3}$ density was shown in Fig.2(b).The deformation of the $510 \mathrm{~kg} / \mathrm{m}^{3}$ density was shown in Fig.2(c).The deformation of the $410 \mathrm{~kg} / \mathrm{m}^{3}$ density was shown in Fig.2(d). The different height of the maximum deformation was shown in Table 2.

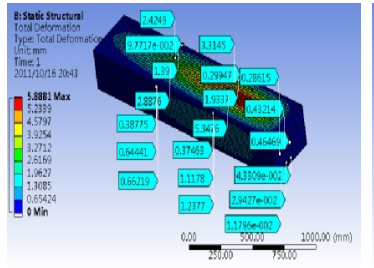

( a )

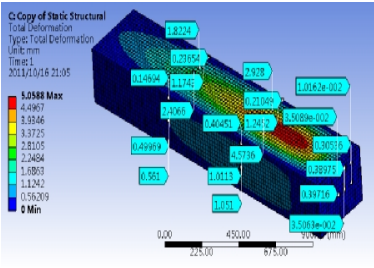

( b )

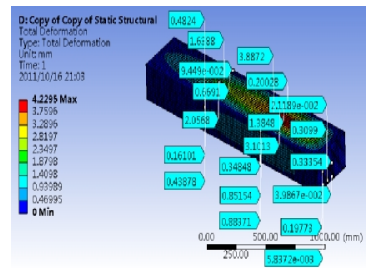

(c)

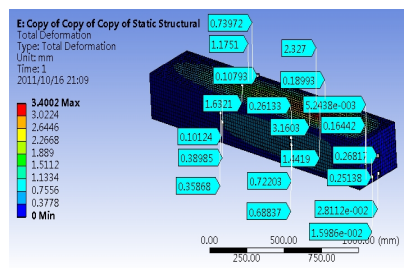

(d)

Fig.2 The deformation of the different height in rectangular silo

Table 2 The different height of the maximum deformation in rectangular silo ( $\mathrm{mm}$ )

\begin{tabular}{cccc}
\hline Fill the fluid density $\left(\mathrm{kg} / \mathrm{m}^{3}\right)$ & The bottom & $600 \mathrm{~mm}$ & $1200 \mathrm{~mm}$ \\
\hline 710 & 5.8881 & 5.3476 & 2.8876 \\
610 & 5.0588 & 4.5736 & 2.4066 \\
510 & 4.2295 & 3.1603 & 2.0568 \\
410 & 3.4002 & 3.0224 & 1.6321
\end{tabular}

The six location of the silo bottom were shown in Fig.3. Its deformation was shown in Table 3.

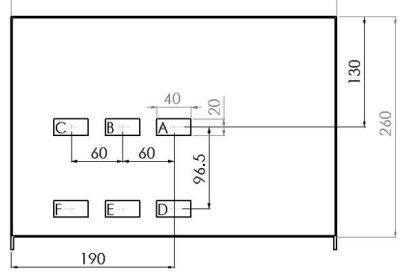

Fig. 3 The plane location of the six points 
Table 3 The bottom surface deformation of rectangular silo ( $\mathrm{mm}$ )

\begin{tabular}{ccccc}
\hline Position & $710 \mathrm{~kg} / \mathrm{m}^{3}$ & $610 \mathrm{~kg} / \mathrm{m}^{3}$ & $510 \mathrm{~kg} / \mathrm{m}^{3}$ & $410 \mathrm{~kg} / \mathrm{m}^{3}$ \\
\hline A & 0.46 & 0.39 & 0.33 & 0.27 \\
B & 0.43 & 0.38 & 0.31 & 0.257 \\
C & 0.29 & 0.31 & 0.20 & 0.167 \\
D & 0.04 & 0.04 & 0.04 & 0.028 \\
E & 0.03 & 0.04 & 0.02 & 0.016 \\
F & 0.01 & 0.01 & 0.006 & 0.005 \\
\hline
\end{tabular}

Thus, with the increase of fluid density, the deformation was increased. The largest stress was the bottom center position and two sides were decreased gradually. Fig. 4 was the deformation of the silo wall under different fluid filling density. The density was respectively $710 \mathrm{~kg} / \mathrm{m}^{3} 、 610 \mathrm{~kg} / \mathrm{m}^{3}$ 、 $510 \mathrm{~kg} / \mathrm{m}^{3}, 410 \mathrm{~kg} / \mathrm{m}^{3}$ in Fig.5 ( a )、 ( b ) 、 ( c )、 ( d ) .

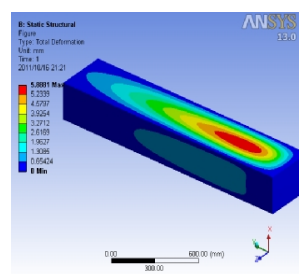

( a )

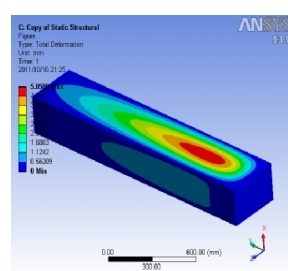

( b )

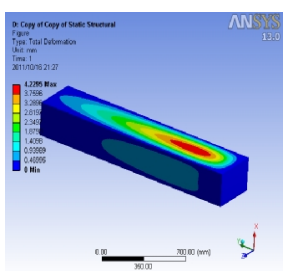

( c )

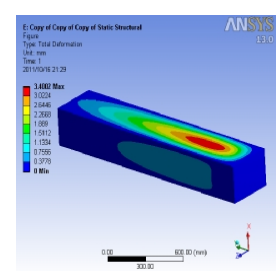

( d )

Fig.4 The strain of the lateral wall under different density in rectangular silo

By the graph, you could see that the biggest deformation was occurred in the bottom. The deformation of the silo wall was the greater with the increase of the filling density. When the moisture content of corns was $75 \%$, the measuring pressure coefficient was 0.42 , the height of the filling silo was $1.6 \mathrm{~m}$ and the friction coefficient between corns and the silo was 0.45 . We analyzed the change of the silo stress and displacement and carried on the intensity check under the normal load and tangential load force. As shown in Fig.5 and Fig.6, we analyzed the force and deformation of the side wall in the silo. The density of the corns was $710 \mathrm{~kg} / \mathrm{m}^{3}$. The loading height was $1 \mathrm{~m}$. The value of the maximal stress was 5.98MPo The value of the maximum deformation ware $\cap 26 \mathrm{~mm}$

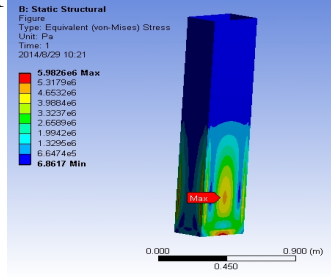

Fig.5 The stress analysis of side wall

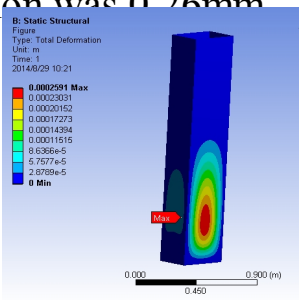

Fig.6 The deformation analysis of side wall

In the same way, we analyzed the force and deformation of the side wall in the silo respectively when the loading height was $1.2 \mathrm{~m} 、 1.4 \mathrm{~m} 、 1.6 \mathrm{~m}, 1.8 \mathrm{~m}$. The loading height was $1.2 \mathrm{~m}$. The maximum stress was $7.63 \mathrm{MPa}$. The maximum deformation was $0.34 \mathrm{~mm}$. The loading height was $1.4 \mathrm{~m}$. The maximum stress was $8.78 \mathrm{MPa}$. The maximum deformation was $0.41 \mathrm{~mm}$. The loading height was $1.6 \mathrm{~m}$. The maximal stress was $9.27 \mathrm{MPa}$. The maximum deformation was $0.45 \mathrm{~mm}$. The loading height was $1.8 \mathrm{~m}$. The maximum stress was $12.45 \mathrm{MPa}$. The maximum deformation was $0.52 \mathrm{~mm}$.

\section{Conclusions}

The results showed that the maximum deformation was happened at the bottom of the silo with the increase of height. The same flat surface pressure distribution were reduced gradually from center to 
around when the filling fluid density was changed, the pressure was increased with the increase of density.

The simulation analysis was showed that the side wall deformation value was changed little with the increase of filling height in the silo according withthe pressure saturation phenomenon. At the same time, the deformation value of the side wall was the basic linear trend after the height of the filling was $1 \mathrm{~m}$ high approximately, namely the pressure saturation phenomenon.

\section{Acknowledgements}

This paper was supported by the funding of the national science and technology plan subproject(NO.2011BAD03B01).

\section{References}

[1] Li , Y.and Puri , V.M. Finite element model prediction of cyclic thermally induced in a scaled bin using elastic plastic constitutive equation.Trans.ASAE.1991 , 34(5) : 2207-2215.

[2] Pablo Vidal, Manuel Guaita, Francisco Ayuga , Analysis of Dynamic Discharge Pressures in Cylindrical Slender Silos with a Flat Bottom or with a1-Iopper: Comparison with Euro- code 1; Biosystems Engineering; 2005 : 335-348.

[3] F.Ayuga , M.Guaita, Discharge and the eccentricity of the hopper in fluence on the silo wall pressure. 14th engineering Mechanical conference , May 21-24, 2000 , Austin .

[4] H.A.Slight. The Measurement of Moisture Content[J]. Measurement and Control , 1989 , 22(2) : 43-44.

[5] S.O.Nelson. Sensing Moisture Contention(Train. Instrument and Measurement , 2000 , 3(1) : 17-20.

[6] Ki-BokKim , Jong-HeonKim , Seung SeokLee. Measurement of grain moisture using microwave attenuation at $10.5 \mathrm{GHz}$ and moisture density. Instrument and Measurement , 2002 , 51(1) : 72-77. 